\title{
Fermentation of Danggui Buxue Tang, an ancient Chinese herbal mixture, together with Lactobacillus plantarum enhances the anti-diabetic functions of herbal product
}

\author{
Rui Guo ${ }^{1,2 \dagger}$, Shuchen Guo ${ }^{1 \dagger}$, Xiong Gao ${ }^{1,3}$, Huaiyou Wang ${ }^{1}$, Weihui Hu ${ }^{1,3}$, Ran Duan ${ }^{1,3}$, Tina T. X. Dong ${ }^{1,3}$
} and Karl W. K. Tsim ${ }^{1,3^{*}}$

\begin{abstract}
Background: Danggui Buxue Tang (DBT), an ancient Chinese herbal decoction containing Astragali Radix and Angelicae Sinensis Radix at a ratio of 5:1, is prescribed for menopausal women. Flavonoids and its flavonoid glycosides are considered as the major active ingredients within the herbal decoction; however, their amount is not controllable during the preparation. Besides, the aglycons within DBT are believed to have better gut absorption and pharmacological efficacy.

Methods: The herbal extract of DBT was fermented with Lactobacillus plantarum. The amounts of flavonoid glucosides and its aglycones in the fermented product were analyzed by using UPLC-MS/MS. In addition, in vitro assays were employed to evaluate the efficacy of the fermented DBT in regulating the activities of a-glucosidase, a-amylase and lipase, as well as their antioxidant capacity (DPPH and T-AOC assays) and anti-glycation property (BSA-methylglyoxal, BSA-fructose, and arginine-methylglyoxal models).

Results: The fermentation of DBT with L. plantarum drove a completed conversion of calycosin-7-O- $\beta$-D-glucoside and ononin to calycosin and formononetin, respectively. The chemical transformation could be probably mediated by $\beta$-glycosidase within the fermented product. Several in vitro assays corresponding to anti-diabetic functions were compared between parental DBT against its fermented product, which included the activities against a-glucosidase, a-amylase and lipase, as well as anti-oxidation and anti-glycation. The fermented DBT showed increased activities in inhibiting a-glycosidase, suppressing DPPH radical-scavenging and anti-glycation, as compared to the original herbal product.
\end{abstract}

Conclusion: These results suggested that DBT being fermented with the probiotic L. plantarum could pave a new direction for fermentation of herbal extract, as to strengthen its pharmacological properties in providing health benefits.

Keywords: Danggui buxue tang, Fermentation, Bioconversion, Anti-diabetic functions

*Correspondence: botsim@ust.hk

${ }^{\dagger}$ Rui Guo and Shuchen Guo contribute equally to this work and joint first authors.

${ }^{1}$ Shenzhen Key Laboratory of Edible and Medicinal Bioresources, HKUST Shenzhen Research Institute, Shenzhen 518057, China

Full list of author information is available at the end of the article

\section{Background}

Type 2 diabetes mellitus (T2DM) is a chronically metabolic syndrome characterized by insulin resistance and pancreatic $\beta$ cell dysfunction, caused by inherited and/ or environmental factors [1]. The global burden of diabetes is increasing worldwide, and the number of diabetic

c) The Author(s) 2020. This article is licensed under a Creative Commons Attribution 4.0 International License, which permits use, sharing, adaptation, distribution and reproduction in any medium or format, as long as you give appropriate credit to the original author(s) and the source, provide a link to the Creative Commons licence, and indicate if changes were made. The images or other third party material in this article are included in the article's Creative Commons licence, unless indicated otherwise in a credit line to the material. If material is not included in the article's Creative Commons licence and your intended use is not permitted by statutory regulation or exceeds the permitted use, you will need to obtain permission directly from the copyright holder. To view a copy of this licence, visit http://creativeco mmons.org/licenses/by/4.0/. The Creative Commons Public Domain Dedication waiver (http://creativecommons.org/publicdomain/ zero/1.0/) applies to the data made available in this article, unless otherwise stated in a credit line to the data. 
patients is expected to rise to 578 million by 2030 and to 700 million by 2045 [2]. Thus, an effective control of blood glucose is the key to prevent complication. Currently, many medicines are listed on the market to treat diabetes, including insulin, metformin, $\alpha$-glucosidase inhibitors, thiazolidinediones and sodium-glucose transport protein 2 [3]; however, these treatments are leading to possible side effects, e.g. gastrointestinal discomfort and hypoglycemia $[4,5]$.

Traditional Chinese medicine (TCM) having less sideeffect and irritation in general has been proposed in treating diabetic patients [6]. In particular, the formulated herbal mixtures have been commonly used in clinics for medical treatment. Among thousands of herbal formulae of TCM, Danggui Buxue Tang (DBT) is one of the simplest. DBT was first described in $<<$ Neiwaishang Bianhuo Lun > > by Li Dongyuan in AD 1247 in China. He described DBT should have: Astragali Radix (AR; roots of Astragalus memebranaceus (Fisch.) Bunge var. mongholicus (Bunge) Hsiao) and Angelicae Sinensis Radix (ASR; roots of Angelica sinensis Oliv.) in 5 to 1 ratio. This herbal mixture has been utilized for nourishing "Qi" and enriching "Blood" for women suffering from menopausal symptoms. Pharmacologically, DBT is able to mitigate menopausal symptoms [7-10], to stimulate immune responses [11] and to accelerate bone regeneration [12, 13]. In addition, DBT has been found to alleviate insulin resistance and to relieve diabetic complication [14-16].

Calycosin-7-O- $\beta$-D-glucoside and ononin (a $7-O-\beta-D-$ glucopyranoside of formononetin) are two major flavonoid glucosides in DBT [17], and which are reported to have potential efficacy associated with diabetes [18]. The pharmacological efficacy of flavonoid glucosides is usually ascribed to their corresponding aglycones that are absorbed much easier than their glycoside forms $[19,20]$. The de-glycosylation, triggered by $\beta$-glucosidase located in the human small intestine, is regarded as a critical process in improving metabolism of flavonoid glucosides $[21,22]$. As a result, the aglycones can be absorbed effectively into blood circulation in attributing anti-diabetic functions [23].

In order to deglycosylate flavonoid glucosides to their corresponding aglycones, as well as to increase intestinal absorption of bioactive compounds, we adopt a bio-conversion method in vitro by means of microbial fermentation in a herbal mixture. Indeed, microorganisms have been employed in fermenting TCM, e.g. probiotic was used to ferment Scutellaria Radix [24], Atractylodis Macrocephalae Rhizoma [25] and red ginseng [26]. To improve the efficacy of DBT in fighting against diabetes, we developed a fermentation process of herbal extract together with Lactobacillus plantarum, a Gram-positive
Lactobacillus, commonly found in fermented food products [27]. Thereafter, we compared the activities of fermented product against its parental herbal extract, which included: (i) the amounts of flavonoid glucosides and its aglycones; and (ii) the inhibitory activities of $\alpha$-glycosidase, $\alpha$-amylase, pancreatic lipase, antioxidant capacity and non-enzymatic glycation.

\section{Materials and methods Chemicals and reagents}

Standards of calycosin-7-O- $\beta$-D-glucoside, ononin, calycosin, formononetin and rutin (Internal standard, IS) were supplied by Testing Laboratory for Chinese Medicine of HKUST (Hong Kong, China). The purity of each standard was $>98 \%$, as detected by HPLC-DAD and ${ }^{13} \mathrm{C}$-NMR analysis. The HPLC grade acetonitrile and formic acid were obtained from Merck (Darmstadt, Germany). Deionized water $(18 \mathrm{MW} / \mathrm{cm})$ was supplied with a Direct- $Q$ water purification system (Millipore, Milford, MA). Acquity UPLC $\mathrm{C}_{18}$ column (Waters, Milford, MA). Tris, p-nitrophenol (PNP), p-nitropheny$\beta$-D-glucopyranoside (PNP-D-Glu), $\alpha$-glucosidase, p-nitrophenyl- $\alpha-D$-glucopyranoside, bovine serum albumin (BSA) and O-phenylenediamine were purchased from Macklin Biochemical (Shanghai, China). DPPH was gained from TCI Chemical Industry (Shanghai, China). Other materials were obtained from Sigma-Aldrich (St. Louis, MO).

\section{Preparation of herbal decoction}

The roots of three-year-old A. memebranaceus var. mongholicus (Astragali Radix; Huangqi; AR) from Shanxi Province [28] and two-year-old A. sinensis roots (Angelicae Sinensis Radix; Danggui; ASR) from Minxian of Gansu Province [29] were collected in 2019. The herbs were identified morphologically by Dr. Tina TX Dong. The voucher specimens of AR (Lot: 20190320) and ASR (Lot: 20190412) were recorded in HKUST Shenzhen Research Institute. In preparing DBT, AR and ASR were weighed according to a ratio of 5:1 and then mixed well. The mixture was boiled in 8 volumes of water $(\mathrm{v} / \mathrm{w})$ for $2 \mathrm{~h}$, and the extraction was repeated twice [12]. The extracts were dried by lyophilization and stored at $-80{ }^{\circ} \mathrm{C}$. The chemical analysis of fermented DBT was carried out as described [8].

\section{Fermentation of DBT extract with L. plantarum}

L. plantarum (GDM 1.191), a facultative heterofermentative lactic acid bacteria, was purchased from Guangdong Microbial Culture Collection Center (ACCC11095; Guangdong, China). L. plantarum is commonly found in most fermented foods [30]. The culture was inoculated twice in MRS broth (10 g peptone, $8.0 \mathrm{~g}$ lab-lemco' 
powder, 4.0 g yeast extract, $20 \mathrm{~g}$ glucose, $2.0 \mathrm{~g}$ di-potassium hydrogen phosphate, $2.0 \mathrm{~g}$ tri-ammonium citrate, 5.0 g sodium acetate with $3 \mathrm{H}_{2} \mathrm{O}, 0.2 \mathrm{~g}$ magnesium sulphate, $0.04 \mathrm{~g}$ manganese sulphate with $4 \mathrm{H}_{2} \mathrm{O}$, and $1 \mathrm{~mL}$ Tween in $80 \mathrm{~L}$ of water, $\mathrm{pH} 5.7 \pm 0.2$; from Hopebio, Qingdao, China) at $37{ }^{\circ} \mathrm{C}$ in anaerobic atmosphere $(10 \%$ $\mathrm{H}_{2}, 10 \% \mathrm{CO}_{2}, 80 \% \mathrm{~N}_{2}$ ) for $24 \mathrm{~h}$ to obtain the strain at end of exponential phase. A stock solution of DBT herbal extract was sterilized with a filter, and which was diluted with MRS medium. The inoculation of $L$. plantarum was adjusted to a concentration of $1 \times 10^{8} \mathrm{CFU} / \mathrm{mL}$, and the fermentation was performed at $37{ }^{\circ} \mathrm{C}$ under anaerobic condition, shaking in $100 \mathrm{rpm}$, until the late stationary phase. The growth of $L$. plantarum was determined by absorbance at $595 \mathrm{~nm}$.

\section{UPLC-MS/MS analysis}

The stock solutions of calycosin-7-O- $\beta$-D-glucoside, ononin, calycosin and formononetin were freshly prepared in methanol at $1 \mathrm{mg} / \mathrm{mL}$. Mixed stock solution $(200 \mu \mathrm{g} / \mathrm{mL}$ each) was prepared. Rutin (IS) at $20 \mu \mathrm{g} /$ $\mathrm{mL}$ was diluted from the stock in methanol. The working standard solutions $(0.092-200 \mu \mathrm{g} / \mathrm{mL})$ for analytes were prepared by a serial diluent of mixed stock solution with methanol. The calibration standard solutions $(0.023-50 \mu \mathrm{g} / \mathrm{mL})$ for analytes were prepared by spiking an appropriate amount of working standard solutions into $150 \mu \mathrm{L}$ blank matrix. The $\mathrm{QC}$ concentrations of tested samples were selected in $0.068,1.84$, and $16.6 \mu \mathrm{g} /$ $\mathrm{mL}$, respectively, at low, medium and high levels. The sample after fermentation $(200 \mu \mathrm{L})$ and IS $(50 \mu \mathrm{L})$ were shaken with vortex for $30 \mathrm{~s}$. Then, adding $800 \mu \mathrm{L}$ methanol to the mixture, vortexed for $2 \mathrm{~min}$ and centrifuged at $10,000 \mathrm{rpm}$ for another $10 \mathrm{~min}$. Then, $2 \mu \mathrm{L}$ supernatant was subjected to UPLC-MS/MS analysis.

UPLC chromatograph coupled with a PerkinElmer QSight ${ }^{\circledR} 210 \mathrm{MS} / \mathrm{MS}$ detector (PerkinElmer, Waltham, MA). The instrument control, analysis and data processing were performed using Simplicity $3 \mathrm{Q}^{\mathrm{TM}}$ software platform. Sample separation was achieved on an Acquity $\mathrm{C}_{18}$ column $(4.6 \times 50 \mathrm{~mm}, 1.7 \mu \mathrm{m})$ with a constant flow rate of $0.3 \mathrm{~mL} / \mathrm{min}$ at $30^{\circ} \mathrm{C}$. The mobile phase was composed of water ( $0.1 \%$ formic acid, A) and acetonitrile (C), using a gradient elution of $80-60 \% \mathrm{~A}$ at $0-4 \mathrm{~min}, 60-10 \% \mathrm{~A}$ at 4-6 $\mathrm{min}, 10-10 \% \mathrm{~A}$ at $6-7 \mathrm{~min}, 10-80 \% \mathrm{~A}$ at $7-8 \mathrm{~min}$, $80-80 \% \mathrm{~A}$ at $8-10 \mathrm{~min}$. The injected volume was set at 2 $\mu \mathrm{L}$. The acquired parameters were optimized as follows: drying gas value, 100; nebulizer gas value, 150; electrospray voltage, $5500 \mathrm{~V}$; HSID temperature, $280{ }^{\circ} \mathrm{C}$. The detection was recorded as MRM negative mode. The proposed analytical method was validated and calculated for specificity, linearity, intra-day and inter-day precision, accuracy, extraction recovery, matrix effect and stability, according with the criteria described in the FDA guidelines for bioanalytical samples.

\section{Enzymatic assays \\ $\beta$-glycosidase}

The assay for $\beta$-glycosidase activity was conducted according to the reported method with minor modifications [31]. Briefly, $100 \mu \mathrm{L}$ fermented sample was acquired by centrifuging at $10,000 \mathrm{rpm}$ for $10 \mathrm{~min}$. The reaction mixture $(1.0 \mathrm{~mL})$ comprised of $1 \mathrm{mM}$ p-nitropheny$\beta$-D-glucopyranoside (PNP-D-Glu), $0.1 \mathrm{M}$ phosphate buffer (pH 6.8) and the sample was incubated at $37^{\circ} \mathrm{C}$ for $30 \mathrm{~min}$. The reaction was stopped by adding $500 \mu \mathrm{L}$ of $0.5 \mathrm{M} \mathrm{NaOH}$ centrifuged at 10,000 rpm for $10 \mathrm{~min}$. The amount of PNP released was measured by absorbance at $405 \mathrm{~nm}$ in a microplate reader.

\section{a-Glucosidase}

The $\alpha$-glucosidase inhibitory property was performed according to the previous method with modification [32]. The tested sample, diluted 5 times with water, was vortexed at $3000 \mathrm{rpm}$ for $5 \mathrm{~min}$. The reaction mixture was composed of the tested sample, phosphate buffer $(0.1 \mathrm{M}, \mathrm{pH} 6.8)$ and $\alpha$-glucosidase $(50 \mu \mathrm{g} /$ $\mathrm{mL})$. Next, p-nitrophenyl- $\alpha$-D-glucopyranoside solution $(10 \mathrm{mM})$ was added to the mixture. The incubation was continued for $20 \mathrm{~min}$ at $37^{\circ} \mathrm{C}$, and which was stopped by adding $100 \mathrm{mM} \mathrm{Na}{ }_{2} \mathrm{CO}_{3}$ solution. Acarbose was used as a positive control at $1 \mu \mathrm{g} / \mathrm{mL}$. The reaction was measured by monitoring $405 \mathrm{~nm}$. The results were presented as a percentage of $\alpha$-glucosidase inhibition, calculated according to the following equation: Inhibition $(\%)=\left(\mathrm{OD}_{-}(\mathrm{ctrl}\right.$. $)-$ OD_sample $) / \mathrm{OD}_{-}(\mathrm{ctrl}$. $) \times 100 \%$.

\section{a-Amylase}

The activity of $\alpha$-amylase was measured using a modified method [33]. Briefly, the tested sample and $\alpha$-amylase solution $(0.2 \mathrm{U} / \mathrm{mL})$ were incubated at $37{ }^{\circ} \mathrm{C}$ for $30 \mathrm{~min}$. Next, 2\% soluble starch solution was added to the mixture, and the incubation was continued for another $20 \mathrm{~min}$ at $37^{\circ} \mathrm{C} . \mathrm{HCl}(1 \mathrm{M})$ was added to terminate the enzymatic reaction, followed by iodine reagent $(5 \mathrm{mg} /$ $\mathrm{mL})$. Acarbose $(200 \mu \mathrm{g} / \mathrm{mL})$ was used as a positive control. The absorbance was measured at $620 \mathrm{~nm}$, and the percent of inhibition was calculated.

Pancreatic lipase: The pancreatic lipase activity was performed using PNPP as substrate [34]. PNPP was used as a substrate in a solution containing: $40 \mathrm{mg}$ PNPP in isopropanol added to $50 \mathrm{mM}$ Tris- $\mathrm{HCl}$ buffer ( $\mathrm{pH} 8.0$ ), $40 \mathrm{mg}$ gum Arabic, $80 \mathrm{mg}$ sodium deoxycholate, and Triton X-100. Orlistat $(50 \mu \mathrm{g} / \mathrm{mL})$ was used as a positive control. Briefly, $20 \mu \mathrm{L}$ of the tested sample was put into 96-well plates, and lipase enzyme solution $(10 \mathrm{mg} /$ 
$\mathrm{mL}$; porcine pancreatic lipase type II, Sigma-Aldrich) was freshly prepared in $50 \mathrm{mM}$ Tris- $\mathrm{HCl}$ buffer $(\mathrm{pH} 8.0)$, stirred until fully dissolved and was then added $80 \mu \mathrm{L}$ to all tests. After $37^{\circ} \mathrm{C}$ for $15 \mathrm{~min}$, the substrate solution was added at $37^{\circ} \mathrm{C}$ for $25 \mathrm{~min}$. Absorbance was recorded at $405 \mathrm{~nm}$.

\section{Antioxidant activity}

DPPH radical-scavenging capacity was estimated according to a previous protocol [35]. Vitamin C $(100 \mu \mathrm{g} / \mathrm{mL})$ was used as a positive control. Briefly, $80 \mu \mathrm{L}$ of each tested sample and $800 \mu \mathrm{L}$ DPPH $(0.5 \mathrm{mmol} / \mathrm{L})$ solubilized in a methanol solution were vortex-mixed and incubated in the dark at $37{ }^{\circ} \mathrm{C}$ for $20 \mathrm{~min}$. DPPH radical was determined by measuring the absorbance at $517 \mathrm{~nm}$. Total antioxidant capacity (T-AOC) was measured by biochemical methods following the manufacturer's instructions (Beijing Solarbio Science and Technology, Beijing, China) [36].

\section{Anti-glycation assay}

The lysine-glucose Maillard reaction was determined, as recorded previously [37]. Glutamic acid and lysine (both at $1.0 \mathrm{M}, 0.2 \mathrm{~mL}$ ) were mixed with $0.8 \mathrm{~mL}$ of tested samples in sodium phosphate buffer $(0.1 \mathrm{M}, \mathrm{pH} 6.8)$ and $0.5 \mathrm{~mL}$ of $0.25 \mathrm{M}$ sodium phosphate buffer at $70{ }^{\circ} \mathrm{C}$ for $2 \mathrm{~h}$. Aminoguanidine $(10 \mathrm{mg} / \mathrm{mL})$ was used as a positive sample. The absorbance was measured at $450 \mathrm{~nm}$ on a microplate reader. The anti-glycation assay in the BSA-fructose model was performed as described [38]. Fructose $(1.5 \mathrm{M}, 0.5 \mathrm{~mL})$ was mixed with $0.5 \mathrm{~mL}$ tested sample, $2.0 \mathrm{~mL}$ sodium phosphate buffer $(0.1 \mathrm{M}, \mathrm{pH}$ 6.8, with $0.02 \%$ sodium benzoate.) at $37^{\circ} \mathrm{C}$ for $2 \mathrm{~h}$. BSA $(30 \mathrm{mg} / \mathrm{mL}, 0.5 \mathrm{~mL})$ was added at $37^{\circ} \mathrm{C}$ for 5 days. Aminoguanidine $(1 \mathrm{mg} / \mathrm{mL})$ was used as a positive control. The fluorescent advanced glycation end-product (AGE) was monitored $(350 \mathrm{~nm}$ as the excitation $/ 420 \mathrm{~nm}$ as emission) using a fluorescence spectrophotometer. Methylglyoxal $(60 \mathrm{mM}, 0.5 \mathrm{~mL})$ was mixed with $0.5 \mathrm{~mL}$ tested sample and $2.0 \mathrm{~mL}$ of sodium phosphate buffer $(0.1 \mathrm{M}$, $\mathrm{pH} 6.8$, with $0.02 \%$ sodium benzoate) at $37^{\circ} \mathrm{C}$ for $2 \mathrm{~h}$. BSA $(30 \mathrm{mg} / \mathrm{mL}, 0.5 \mathrm{~mL})$ was added at $37^{\circ} \mathrm{C}$ for 5 days. Aminoguanidine $(1 \mathrm{mg} / \mathrm{mL})$ was used as a control. The fluorescent AGE was monitored ( $350 \mathrm{~nm}$ as the excitation $1420 \mathrm{~nm}$ as emission) was measured on the fluorescence spectrophotometer. In arginine-methylglyoxal assay, methylglyoxal $(60 \mathrm{mM}, 0.5 \mathrm{~mL})$ was mixed with $0.5 \mathrm{~mL}$ of tested samples and $2.0 \mathrm{~mL}$ sodium phosphate buffer $\left(0.1 \mathrm{M}, \mathrm{pH} 6.8\right.$, with $0.02 \%$ sodium benzoate.) at $37^{\circ} \mathrm{C}$, $2 \mathrm{~h}$. Arginine ( $60 \mathrm{mM}, 0.5 \mathrm{~mL}$ ) was added to all sets, and the mixtures were incubated at $37{ }^{\circ} \mathrm{C}$ for 5 days. Aminoguanidine $(1 \mathrm{mg} / \mathrm{mL})$ was used as a positive sample.
Then, the fluorescent AGE was monitored (350 $\mathrm{nm}$ as the excitation /420 $\mathrm{nm}$ as emission) was measured.

\section{Methylglyoxal scavenging}

Methylglyoxal scavenging was conducted by HPLC method according to a previously published method with modification [39]. Methylglyoxal was derivatized with O-phenylenediamine (O-PD) to form 2-methylquinoxaline (2-MQ), highly specific for methylglyoxal. Methylglyoxal and O-PD were dissolved in phosphate buffer $(0.1 \mathrm{M}, \mathrm{pH} 6.8)$ to 10 and $50 \mathrm{mM}$. Aminoguanidine $(1 \mathrm{mg} / \mathrm{mL})$ was used as a control. The mixture of methylglyoxal $(50 \mathrm{mM}, 0.1 \mathrm{~mL})$ with the sample $(0.4 \mathrm{~mL})$ was incubated at $37^{\circ} \mathrm{C}$ for $4 \mathrm{~h}$. Then, O-PD $(0.2 \mathrm{~mL})$ was added into all sets. The samples were kept for $30 \mathrm{~min}$ for undergoing derivatization reaction between methylglyoxal and O-PD. Analysis of 2-MQ was performed on a Waters 2695 HPLC platform (Waters Corporation, Milford, MA) and carried out by a Zorbax SB-C18 column $(4.6 \times 250 \mathrm{~mm}, 5 \mu \mathrm{m}$, Agilent Technologies, Palo Alto, CA). The mobile phase for HPLC system consisted of pure methanol (solvent A) and pure Millipore water (solvent B) with a constant flow rate set at $1.0 \mathrm{~mL} / \mathrm{min}$. An injection volume was $10 \mu \mathrm{L}$. The linear gradient for elution was: 0-35 min, 5-100\% A; 35-45 min, $100-5 \%$; followed by $5 \mathrm{~min}$ to re-equilibrate the system. 2-MQ was detected at $315 \mathrm{~nm}$ using a DAD detector having a retention time at $20.09 \mathrm{~min}$. The peak area of 2-MQ in each sample was integrated. The methylglyoxal scavenging was calculated using the percentage (\%) calculated from the homologous equation in BSA-fructose model.

\section{Results}

\section{Method development and optimization}

The chemical characterization of DBT was reported previously [8]. HPLC fingerprint of DBT, or fermented DBT, was shown for quality control (Additional file 1. Fig. S1). Besides, the amounts of major flavonoids in DBT, i.e. calycosin-7-O- $\beta$-D-glucoside, ononin, calycosin, formononetin, were subjected to UPLC-MS/MS analysis (Fig. 1a). Quantitative analysis of targeted analyte was performed by multiple reactions monitoring (MRM) in negative ion mode for better signal intensity. The parameters, including entrance voltage (EV), collision energy (CE) and collision cell lens (CCL), were optimized in accord to the peak intensity of analyte to minimize matrix effect, as well as to increase overall sensitivity. The optimized MRM parameters of the analytes, including IS (rutin), were shown in Additional file 1. Table S1. The deprotonated molecules $[\mathrm{M}-\mathrm{H}]^{-}$as precursor ions were shown for flavone aglycones, i.e. calycosin and formononetin. For the corresponding flavonoid glycosides, calycosin-7-O- $\beta$-D-glucoside and ononin, the anionic 
a<smiles>COc1ccc(-c2coc3cc(OC4OCC5COC(O)C(O)C(O)C(O)C5O4)ccc3c2=O)cc1O</smiles>

calycosin-7-0- $\beta$-glu

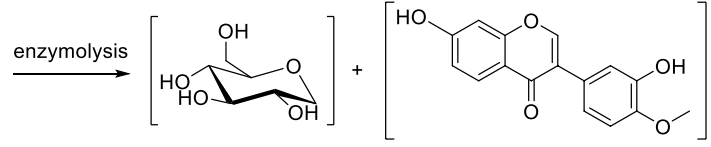

calycosin<smiles></smiles>

ononin<smiles>COc1ccc(-c2coc3cc(O)ccc3c2=O)cc1</smiles>

formononetin b calycosin-7-0- $\beta$-glu

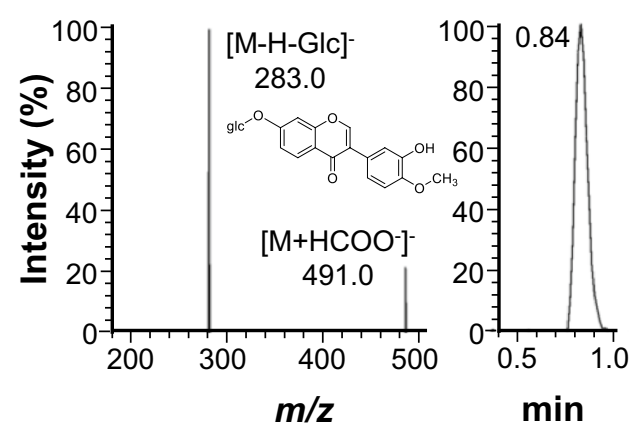

ononin

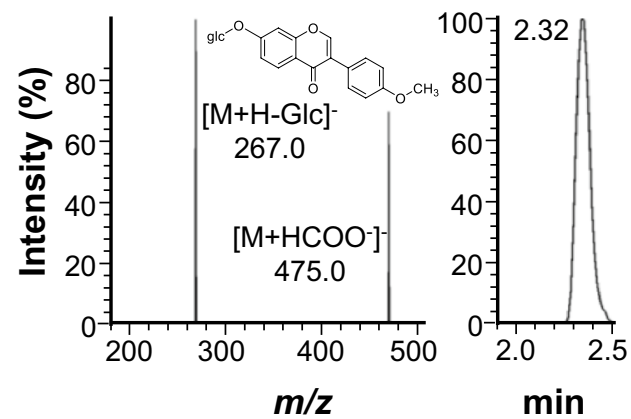

calycosin

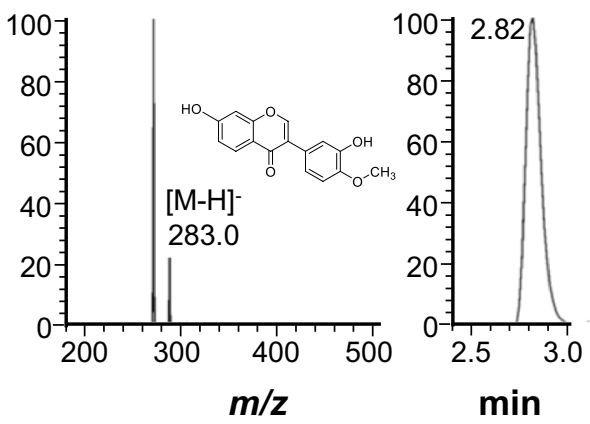

formononetin

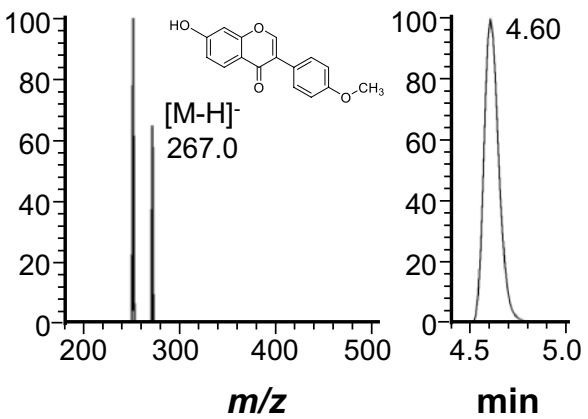

Fig. 1 Conversion of flavonoid glycosides and its chemical analysis. a Conversion of calycosin-7-O- $\beta$-D-glucoside and ononin to calycosin and formononetin, examples of hydrolysis of flavonoid glycosides mediated by an enzymatic reaction. $\mathbf{b}$ Representative UPLC-MS/MS spectra of calycosin-7-O- $\beta$-D-glucoside, calycosin, ononin, and formononetin, showing precursor ion to product ion transitions, and their proposed fragmentation pathways

adducts $\left[\mathrm{M}+\mathrm{HCOO}^{-}\right]^{-}$were detected as precursor ion, then $\mathrm{HCOOH}$ ion and sugar moiety could be lost from the precursor ion to form the deprotonated and de-glycosylated molecule $[\mathrm{M}-\mathrm{H}-\mathrm{Glc}]^{-}$. The UPLC chromatogram and related MS transition spectrum were presented in Fig. $1 \mathrm{~b}$.

To validate the analytical method, a series of attributes were estimated, e.g. specificity, linearity, calibration range, sensitivity, precision, accuracy, extraction efficiency, matrix effect and stability. No interference of endogenous substance was found in the analytes at LLOQ, and all peaks possessed a good separation and dispersion (Fig. 2). The linearity of method for all analytes were investigated in the concentration range of $0.023-50 \mu \mathrm{g} / \mathrm{mL}$, with the coefficient of determination $\left(R^{2}\right)$ greater than 0.99 (Table 1), which was acceptable for 

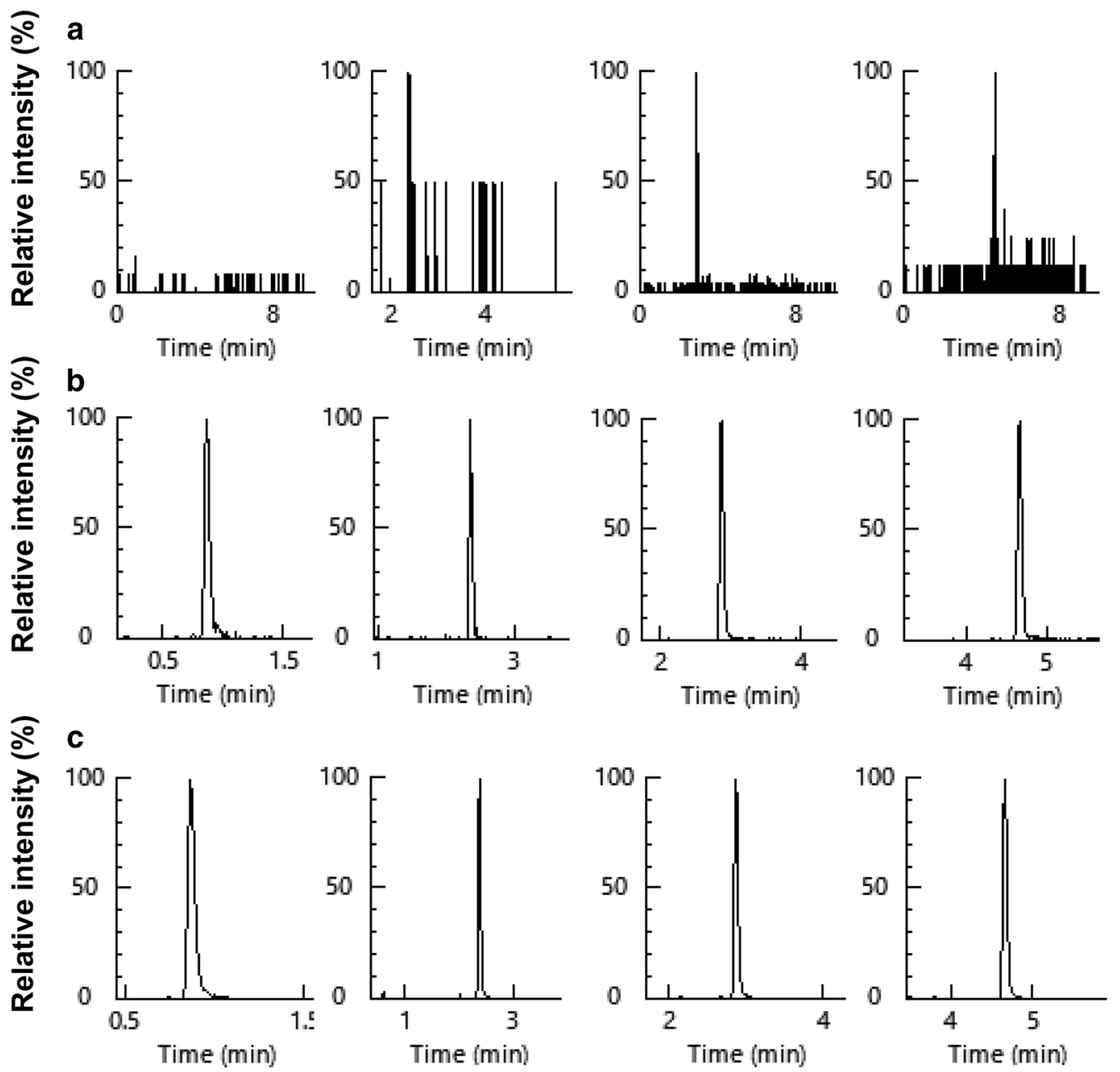

calycosin-7-0- $\beta$-glu

ononin

formononetin

calycosin

Fig. 2 Chromatographic analysis of flavonoids. Representative chromatograms of calycosin-7-O-ß-D-glucoside, ononin, formononetin and calycosin under a Blank matrix; b Blank matrix spiked with the four analytes LLOQ; and $\mathbf{c}$ The products at $6 \mathrm{~h}$ of fermentation

Table 1 Linearity and sensitivity of UPLC-MS/MS assay for standards in fermented DBT

\begin{tabular}{|c|c|c|c|c|c|}
\hline Analyte & Calibration curve & $R^{2 \mathrm{a}}$ & Linear range $(\mu \mathrm{g} / \mathrm{mL})$ & LLOQ $(\mu \mathrm{g} / \mathrm{mL})$ & $\operatorname{LOD}(\mu \mathrm{g} / \mathrm{mL})$ \\
\hline Cal-O- $\beta-g^{\prime} u^{d}$ & $y=0.1032 x+0.0397$ & 0.9986 & $0.023-50$ & 0.023 & 0.008 \\
\hline Ononin & $y=0.2496 x+0.1498$ & 0.9967 & $0.023-50$ & 0.023 & 0.008 \\
\hline Calycosin & $y=4.4401 x+4.0138$ & 0.9909 & $0.023-50$ & 0.023 & 0.008 \\
\hline Formononetin & $y=3.8437 x+3.2295$ & 0.9923 & $0.023-50$ & 0.023 & 0.008 \\
\hline
\end{tabular}

a The calibration curve was constructed by plotting the peak area versus the concentration of each analyte. Each calibration curve was derived from 6 data points, $n=3 . R^{2}$, coefficient of determination

$\angle L O Q$ lower limit of quantification

$\angle O D$ limit of detection

Cal-O- $\beta$-glu ${ }^{\text {d }}$ calycosin-7-O- $\beta$-D-glucoside 
the quantification of samples. The sensitivity was evaluated by determination of LODs and LLOQs for each analyte (Table 1). Each analyte showed a LLOQ lower than $0.023 \mu \mathrm{g} / \mathrm{mL}$. These findings suggested that the established MS method was sensitive enough to determine all analytes in the fermented broth.

The intra- and inter- day assay performances were assessed by analyzing 3-level of QC samples (LQC, MQC and HQC) in six replicates, representing an entire calibrating range. The RE values of intra- and inter-day accuracies were in the range of $-12.8 \%$ to $11.5 \%$ and $-10.8 \%$ to $11.2 \%$, respectively (Table 2 ). For intra- and inter-assay precisions, the RSDs were ranged from $0.84 \%-4.52 \%$ and $1.02 \%-8.51 \%$, respectively. The above values were below $15 \%$, demonstrating favorable data for acceptance criteria. The extracting efficiencies and matrix effects of analytes were determined in 6 replicates, and the results were summarized in Table 3. The extraction at three concentrations were satisfactory, as confirmed by recovery of 93.2-103.8\%, indicating the acceptability and accuracy of this method. In terms of matrix effect, there was no significant matrix effect observed under current conditions, i.e. $89.6-114.3 \%$, which was within the range of $80-120 \%$ [31]. In addition, the RSDs of extraction efficiencies and matrix effects for 3-level QC samples were below 15\%, demonstrating a favorable sample preparation. The tests for assessing stability of established method were performed in auto-sampler at $4{ }^{\circ} \mathrm{C}$ for $48 \mathrm{~h}$ in a $8 \mathrm{~h}$ interval, having RSD values in a range of $1.48-5.81 \%$ and $\mathrm{RE} \%$ of $-7.68-14.80 \%$ (Table 3 ). The results suggested the sample stability during storage.
Fermentation of DBT with L. plantarum

Probing the possible changes of DBT ingredients, $L$. plantarum was fermented in the presence of DBT for different periods. The validated method, as mentioned above, was applied to determine the concentrations of four flavonoids in fermented products. The parental DBT without fermentation, i.e. at time zero, contained calycosin-7-O- $\beta$-D- glucoside with its aglycon calycosin, as well as ononin with its aglycon formononetin (Fig. 3). The parental DBT contained calycosin-7-O- $\beta$-Dglucoside at $0.54 \mu \mathrm{g}$, ononin at $0.36 \mu \mathrm{g}$, calycosin $0.34 \mu \mathrm{g}$ and formononetin at $0.12 \mu \mathrm{g}$ per $\mathrm{mg}$ of dried herbal extract. According to the progression of fermentation, the amount of calycosin-7-O- $\beta$-D-glucoside decreased, and contrary the amount of calycosin was increased. This change was started to be significant after $12 \mathrm{~h}$ of fermentation. At $36 \mathrm{~h}$ of fermentation, the amount of calycosin-7-O- $\beta$-D-glucoside decreased to a minimum. This observation was revealed in a pair of ononin and formononetin. In contrast, the conversion was more robust in this scenario (Fig. 3). The completed conversion of ononin to formononetin was revealed after $24 \mathrm{~h}$ of fermentation. This conversion could be an outcome of enzymatic hydrolyzing of flavonoid glucosides to its aglycons.

The growth (i.e. $\mathrm{OD}_{595}$ absorbance) and $\mathrm{pH}$ value of L. plantarum being fermented with or without DBT were determined. There was no apparent growth in the first $3 \mathrm{~h}$, and however an exponential growth was observed thereafter (Fig. 4). The growth started to be a plateau at about $24 \mathrm{~h}$ of fermentation. In the presence of DBT or not, the growth of $L$. plantarum did not

Table 2 Intra-day and inter-day precision and accuracy for UPLC-MS/MS assay of standards in fermented DBT

\begin{tabular}{|c|c|c|c|c|c|c|c|}
\hline \multirow[t]{2}{*}{ Analyte } & \multirow[t]{2}{*}{ Spiked $(\mu \mathrm{g} / \mathrm{mL})$} & \multicolumn{3}{|c|}{ Intra-day $(n=6)^{a}$} & \multicolumn{3}{|c|}{ Inter-day $(n=18)^{b}$} \\
\hline & & $\begin{array}{l}\text { Measured } \\
(\mu \mathrm{g} / \mathrm{mL})\end{array}$ & $\begin{array}{l}\text { Precision } \\
\text { (RSD\%) }\end{array}$ & Accuracy (RE\%) & $\begin{array}{l}\text { Measured } \\
(\mu \mathrm{g} / \mathrm{mL})\end{array}$ & $\begin{array}{l}\text { Precision } \\
\text { (RSD\%) }\end{array}$ & Accuracy (RE\%) \\
\hline \multirow[t]{3}{*}{ Cal-O- $\beta$-glu } & 0.07 & 0.07 & 4.52 & 2.77 & 0.07 & 4.09 & 4.24 \\
\hline & 1.84 & 1.91 & 0.84 & 4.16 & 1.98 & 2.30 & 7.93 \\
\hline & 16.60 & 16.30 & 2.04 & -1.97 & 16.70 & 1.74 & -0.14 \\
\hline \multirow[t]{3}{*}{ Ononin } & 0.07 & 0.07 & 2.83 & -2.30 & 0.06 & 6.09 & -5.03 \\
\hline & 1.84 & 2.03 & 1.92 & 10.20 & 2.09 & 2.48 & 13.90 \\
\hline & 16.60 & 14.80 & 2.32 & -12.80 & 14.90 & 1.44 & -10.30 \\
\hline \multirow[t]{3}{*}{ Calycosin } & 0.07 & 0.07 & 2.06 & 4.42 & 0.06 & 8.51 & -10.80 \\
\hline & 1.84 & 2.05 & 1.32 & 11.50 & 2.04 & 2.56 & 11.20 \\
\hline & 16.60 & 15.50 & 2.21 & -7.58 & 16.00 & 1.10 & -6.51 \\
\hline \multirow[t]{3}{*}{ Formononetin } & 0.07 & 0.07 & 2.61 & 3.93 & 0.06 & 2.44 & -6.58 \\
\hline & 1.84 & 1.99 & 1.91 & 7.99 & 1.99 & 2.63 & 7.88 \\
\hline & 16.60 & 15.60 & 2.20 & -6.87 & 15.80 & 1.02 & -4.90 \\
\hline
\end{tabular}

\footnotetext{
a The intra-day analysis refers to the sample examined for 6 replicates within one day

b The inter-day analysis refers to the sample examined in duplicates over 3 consecutive days

Cal-O- $\beta$-glu calycosin-7-O- $\beta-D-g l u c o s i d e$
} 
Table 3 Extraction efficiency, matrix effect and stability for UPLC-MS/MS assay of flavonoids in fermented DBT

\begin{tabular}{|c|c|c|c|c|c|c|c|}
\hline \multirow[t]{2}{*}{ Analyte } & \multirow[t]{2}{*}{ Spiked $(\mu \mathrm{g} / \mathrm{mL})$} & \multicolumn{2}{|c|}{ Extraction efficiency $^{\mathrm{a}}(n=6)$} & \multicolumn{2}{|c|}{ Matrix effects ${ }^{b}(n=6)$} & \multicolumn{2}{|c|}{ Autosampler stability ${ }^{c}(n=6)$} \\
\hline & & Measured (\%) & RSD (\%) & Measured (\%) & RSD (\%) & Accuracy (RE\%) & RSD (\%) \\
\hline \multirow[t]{3}{*}{ Cal-O- $\beta-$ glu } & 0.07 & 101.20 & 2.49 & 114.30 & 8.18 & 4.29 & 11.50 \\
\hline & 1.84 & 95.00 & 2.45 & 104.10 & 1.82 & 8.57 & 2.51 \\
\hline & 16.60 & 99.20 & 1.82 & 110.20 & 1.13 & 1.33 & 1.48 \\
\hline \multirow[t]{3}{*}{ Ononin } & 0.07 & 102.10 & 6.90 & 99.80 & 3.89 & 2.82 & 5.81 \\
\hline & 1.84 & 93.30 & 2.95 & 97.20 & 2.61 & 14.80 & 1.95 \\
\hline & 16.60 & 100.00 & 3.42 & 81.50 & 0.91 & -7.68 & 2.41 \\
\hline \multirow[t]{3}{*}{ Calycosin } & 0.07 & 103.80 & 1.76 & 99.50 & 2.36 & -0.51 & 4.39 \\
\hline & 1.84 & 93.30 & 2.43 & 98.20 & 1.10 & 12.30 & 2.82 \\
\hline & 16.60 & 99.80 & 2.86 & 89.60 & 1.00 & -7.28 & 3.29 \\
\hline \multirow[t]{3}{*}{ Formononetin } & 0.07 & 100.10 & 1.62 & 100.30 & 3.21 & 15.50 & 3.76 \\
\hline & 1.84 & 93.20 & 1.91 & 99.70 & 1.25 & 8.90 & 3.26 \\
\hline & 16.60 & 99.70 & 2.68 & 90.50 & 0.95 & -7.12 & 3.39 \\
\hline
\end{tabular}

${ }^{a}$ Extraction efficiency $(\%)=100 \% \times$ amount found (pre-extraction) /amount found (after extraction). The data was presented as average of 6 independent determinations, and the SD was $<5 \%$ of the Mean, which was not shown for clarity

b Matrix effects $(\%)=100 \% \times$ amount found (after extraction)/amount spiked.The data was presented as average of six independent determinations, and the SD was $<5 \%$ of the Mean, which was not shown for clarity

c Autosampler stability (\%) $=100 \% \times$ amount found (pre extraction) - amount spiked/amount spiked. The data was presented as average of 6 independent determinations, and the SD was $<5 \%$ of the Mean, which was not shown for clarity

Cal-O- $\beta$-glu calycosin-7-O- $\beta$-D-glucoside
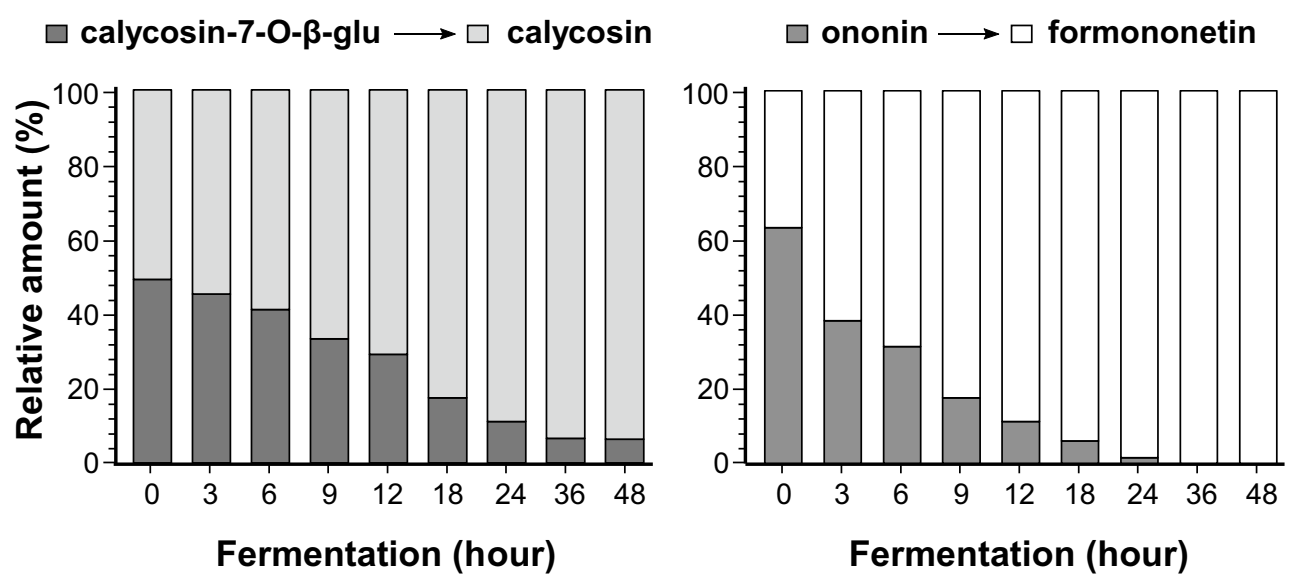

Fig. 3 Hydrolysis of flavonoid glycosides during fermentation. The fermentation was started at time zero having L. plantarum $1 \times 10^{7}$ CFU/mL with DBT herbal extract at $21.6 \mathrm{mg} / \mathrm{mL}$ in MRS at $37^{\circ} \mathrm{C}$ for various time points, as indicated. The amounts of calycosin-7-O- $\beta$-D-glucoside, calycosin, ononin and formononetin were determined by UPLC-MS/MS as in Fig. 1. The relative amount of each flavonoid was shown. Values are in mean \pm SD, $n=5$. The SD is not shown for clarity

show much difference. The $\mathrm{pH}$ decrement was accompanied by culture growth during the whole fermentation process. No significant difference was observed for the two culture conditions (Fig. 4). Because of the conversion of flavonoid glycoside during fermentation, the enzymatic activity of $\beta$-glucosidase, an enzyme catalyzes the hydrolysis of the glycosidic bonds to terminal non-reducing residues in $\beta$-D-glucosides and oligosaccharides, was determined. The release of PNP from p-nitrophenyl-D-glucopyranoside (PNP-D-Glu), reflecting enzymatic activity $\beta$-glucosidase, was compared in the fermented product with or without DBT. In present of DBT, the release of PNP was increased markedly, reaching a plateau after $24 \mathrm{~h}$ of fermentation: this induction was significantly higher than that of L. plantarum without DBT (Fig. 4). This phenomenon suggested that the inclusion of DBT in fermentation 


\section{$\circ$ L. plantarum $\quad \bullet$ L. plantarum + DBT}
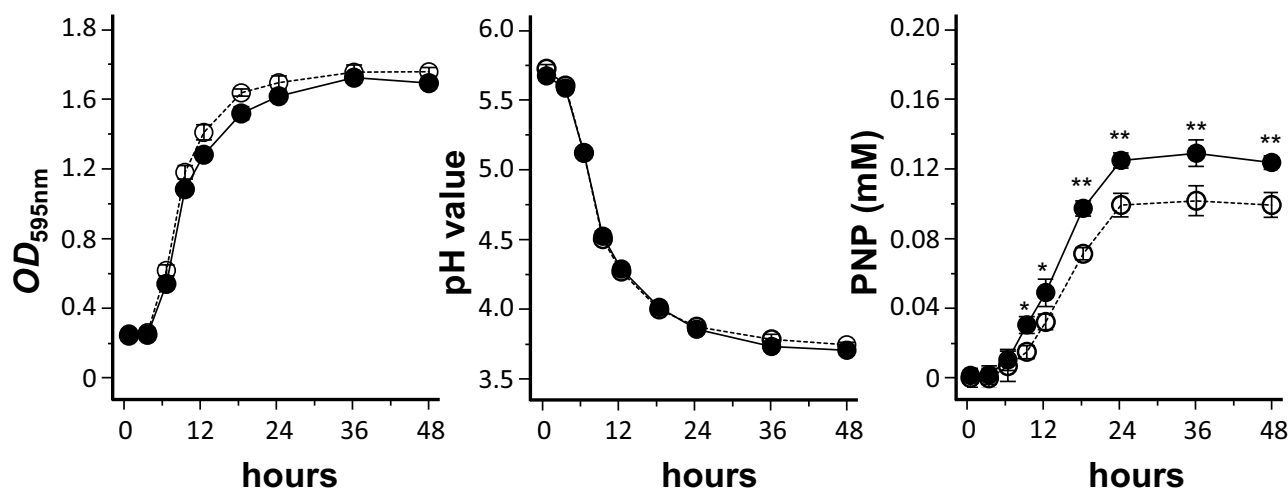

Fig. 4 Growth of $L$. plantarum and activity of $\beta$-glucosidase in the presence of DBT. The fermentation was started at time zero having $L$. plantarum $1 \times 10^{7} \mathrm{CFU} / \mathrm{mL}$, or with DBT herbal extract at $43.2 \mathrm{mg} / \mathrm{mL}$, in MRS at $37^{\circ} \mathrm{C}$ for various time points, as indicated. The changes of growth (OD595 absorbance), $\mathrm{pH}$ value and release of $\mathrm{p}$-nitrophenol (PNP, corresponding $\beta$-glucosidase activity) during the fermentation were measured in each time point. The fermented product $(0.2 \mathrm{~mL})$ was used for assayed of $\beta$-glucosidase. Values are represented as mean $\pm S D, n=5$. The significance difference was assessed by one-way ANOVA: ${ }^{*} p<0.05$ and ${ }^{* *} p<0.01$ vs. L. plantarum group (no DBT)

could cause L. plantarum to produce higher amount of $\beta$-glycosidase in hydrolyzing flavonoid glycosides.

\section{Fermented product with DBT shows better anti-diabetic functions}

The fermented products were tested for possible functions in diabetics. In contrast to $\beta$-glucosidase, $\alpha$-glucosidase breaks down starch and disaccharides to glucose. Inhibitors of $\alpha$-glucosidase, e.g. acarbose and voglibose, are common drugs for diabetes mellitus type 2 , which are aiming to prevent the digestion of carbohydrate to simple sugar [33]. The usage of these inhibitors could lead to reduction of blood sugar. Here, DBT, fermented or not fermented, was tested for activity in inhibiting $\alpha$-glucosidase. The culture medium of L. plantarum and DBT showed inhibition of about 30 to $50 \%$ (Fig. 5). After fermentation, the inhibition activity was markedly increased: the inhibition was close to $90 \%$ after $48 \mathrm{~h}$ of fermentation. Without DBT, the fermented L. plantarum showed no increase activity at all. Acarbose served as a control showing inhibition, similar to that of fermented DBT. $\alpha$-Amylase, an enzyme catalyzes the hydrolysis of starch into simple sugar, and lipase, an enzyme catalyzes hydrolysis of fat, were assayed for the DBT fermented products. DBT alone without fermentation showed low inhibition on the activities of $\alpha$-amylase and lipase. Medium of L. plantarum showed inhibition at 30\%; however, the fermented DBT with $L$. plantarum did not change the pattern (Fig. 5). The positive controls of $\alpha$-amylase (acarbose) and lipase (orlistat) showed significant inhibition (Fig. 5).
The DPPH radical scavenging capacity of DBT, with or without fermentation, was measured. DBT alone showed DPPH radical scavenging, having $\sim 50 \%$ reduction. Fermentation with $L$. plantarum could markedly enhance the scavenging activity of DBT: this increase was in a time-dependent manner (Fig. 6). Fermentation at $48 \mathrm{~h}$ increased the scavenging activity of DBT to almost $90 \%$, better than the positive control (vitamin $\mathrm{C}$ ). The total antioxidant capacity (T-AOC) was measured in DBT showing induction of T-AOC (Fig. 6). In a time-dependent manner, the fermentation of DBT with L. plantarum possessed robust activity of T-AOC, e.g. $15.0 \mathrm{U} / \mathrm{mL}$ of T-AOC after $48 \mathrm{~h}$ of fermentation.

Glycation is a reaction of free reducing sugars with free amino groups of protein, DNA and lipid forming Amadori products, subsequently which leads to the formation of advanced glycation end product (AGE). This process leads to a loss of protein function and impaired cell functions. The glycation reaction is highly accelerated under hyperglycemia, implicating the pathogenesis of diabetics and aging. In addition, oxidative stress plays a role in forming AGEs, and thus which has been implicated in causing the progression of diabetes [34]. In view of this, the possible functions of anti-glycation of DBT with or without L. plantarum fermentation were determined here. In Maillard reaction, lysine-glucose was detected as brown color, revealed under absorbance at $450 \mathrm{~nm}$, after heating at $70{ }^{\circ} \mathrm{C}$ for $2 \mathrm{~h}$. DBT, or L. plantarum medium, showed the browning inhibition, and the inclusion of two of them did not show increase of inhibition (Fig. 7). The fermentation of DBT however could increase the browning inhibition, reaching $\sim 80 \%$ of inhibition. The 


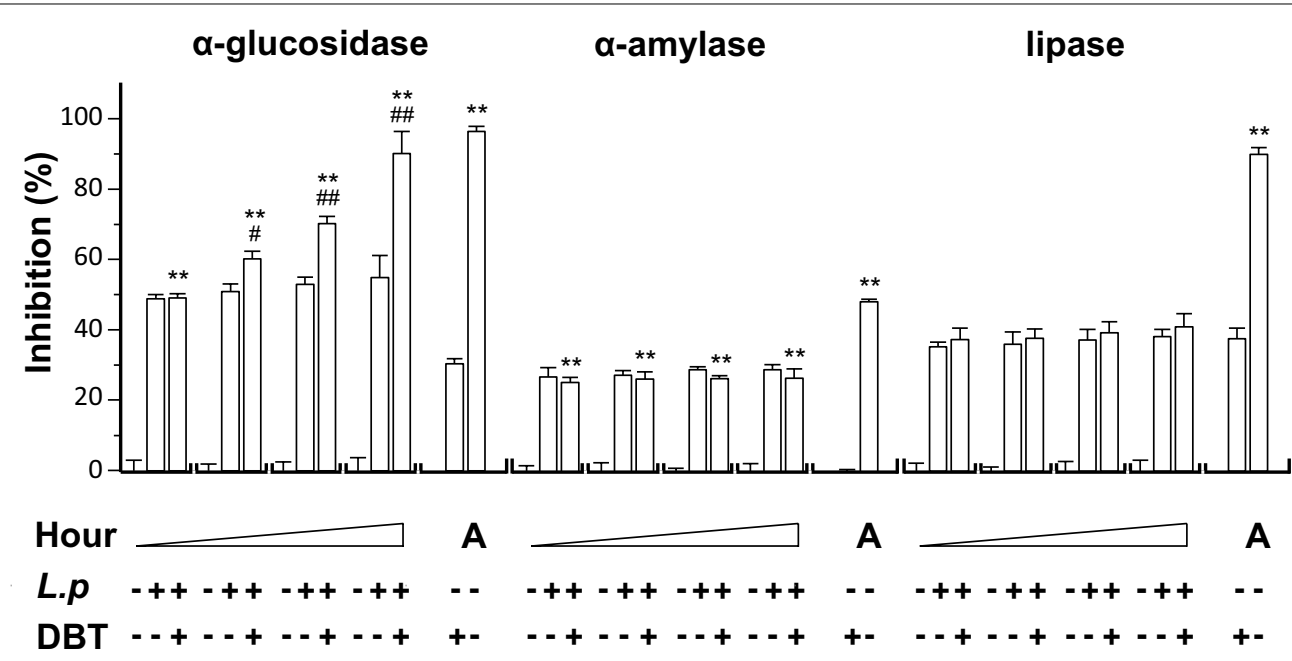

Fig. 5 The fermented product having DBT shows stronger a-glucosidase activity. The effects of L. plantarum fermented DBT on a-glucosidase, a-amylase, and pancreatic lipase were measured. The fermentation medium was used as a control group. The fermentation was started with $L$. plantarum $1 \times 10^{7} \mathrm{CFU} / \mathrm{mL}$, or with DBT herbal extract at $43.2 \mathrm{mg} / \mathrm{mL}$, in MRS at $37^{\circ} \mathrm{C}$ for $0,9,18$, and $48 \mathrm{~h}$, as indicated. The products ( $0.2 \mathrm{~mL}$ ) in all cases were used for assay. DBT dissolved in MRS at $43.2 \mathrm{mg} / \mathrm{mL}$ without $L$. plantarum and acarbose (A) served as positive controls for a-glucosidase (at $1 \mu \mathrm{g} / \mathrm{mL}$ ) and a-amylase (at $200 \mu \mathrm{g} / \mathrm{mL}$ ). Orlistat $(O ; 50 \mu \mathrm{g} / \mathrm{mL}$ ) is a positive control. Values are represented as mean $\pm S D, n=6$, as a percentage of inhibition against control (no drug). The significance was assessed by one-way ANOVA: ${ }^{*} p<0.05$ and ${ }^{* *} p<0.01$ vs DBT group, and ${ }^{\#} p<0.05$ and $\#$ \# 0.01 vs L. plantarum group (L.P)
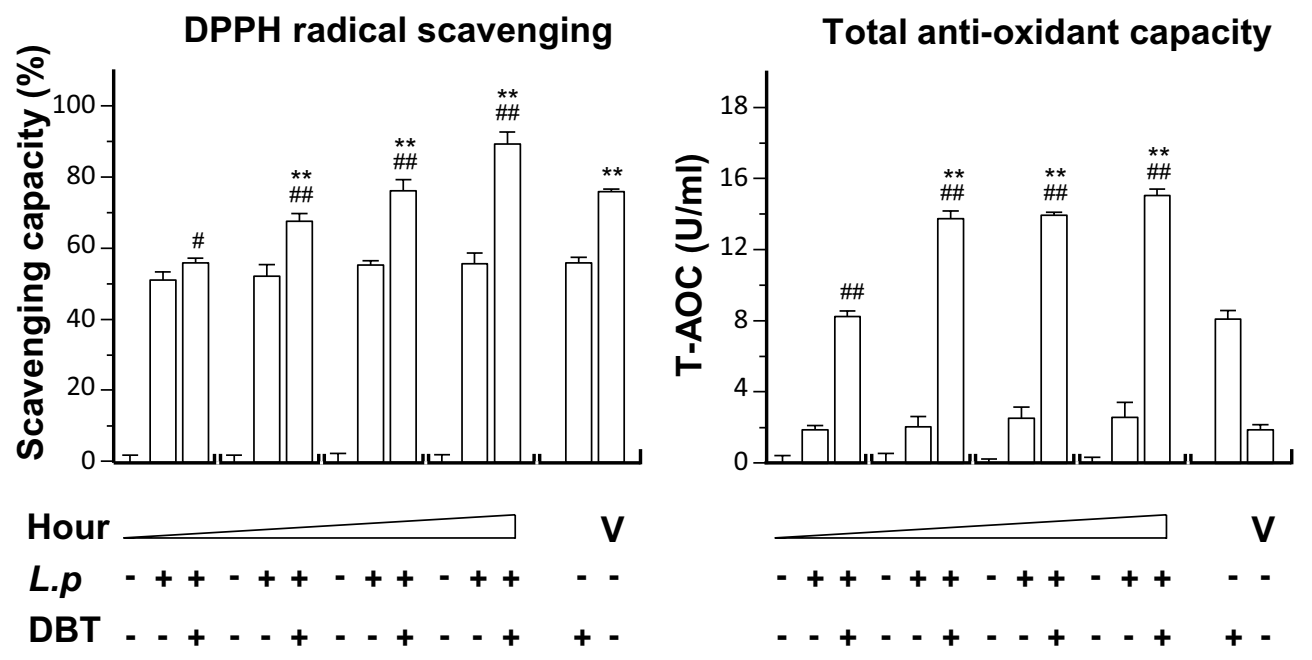

Fig. 6 The fermented product having DBT shows stronger anti-oxidative activity. The effects of L. plantarum fermented DBT on DPPH radical scavenging and total antioxidant capacity (T-AOC) were measured. The fermentation medium was used as a control group. The fermentation was started with L. plantarum $1 \times 10^{7} \mathrm{CFU} / \mathrm{mL}$, or with DBT herbal extract at $43.2 \mathrm{mg} / \mathrm{mL}$, in MRS at $37^{\circ} \mathrm{C}$ for $0,9,18$, and 48 h, as indicated. The products $(0.2 \mathrm{~mL})$ in all cases were used for assay. DBT dissolved in MRS at $43.2 \mathrm{mg} / \mathrm{mL}$ without L. plantarum and Vitamin C (V) served as positive controls at $100 \mu \mathrm{g} / \mathrm{mL}$ for DPPH scavenging and T-AOC). Values are represented as mean $\pm S D, n=6$, as a percentage of inhibition against control (no drug). The significance was assessed by one-way ANOVA: ${ }^{*} p<0.05$ and ${ }^{* *} p<0.01$ vs DBT group, and ${ }^{\#} p<0.05$ and ${ }^{\# \#} p<0.01$ vs L. plantarum group (L.p)

BSA-fructose model was used here to further demonstrate the anti-glycation of DBT. The fluorescent AGE was monitored using a fluorescence spectrophotometer (350 $\mathrm{nm}$ as excitation /420 $\mathrm{nm}$ as emission). DBT itself showed glycation inhibition, and which was robustly enhanced by fermented together with $L$. plantarum (Fig. 7). This enhancement was in a time-dependent manner.

The BSA-methylglyoxal model represents the middle stage of protein glycation, leading to formation of AGE. 


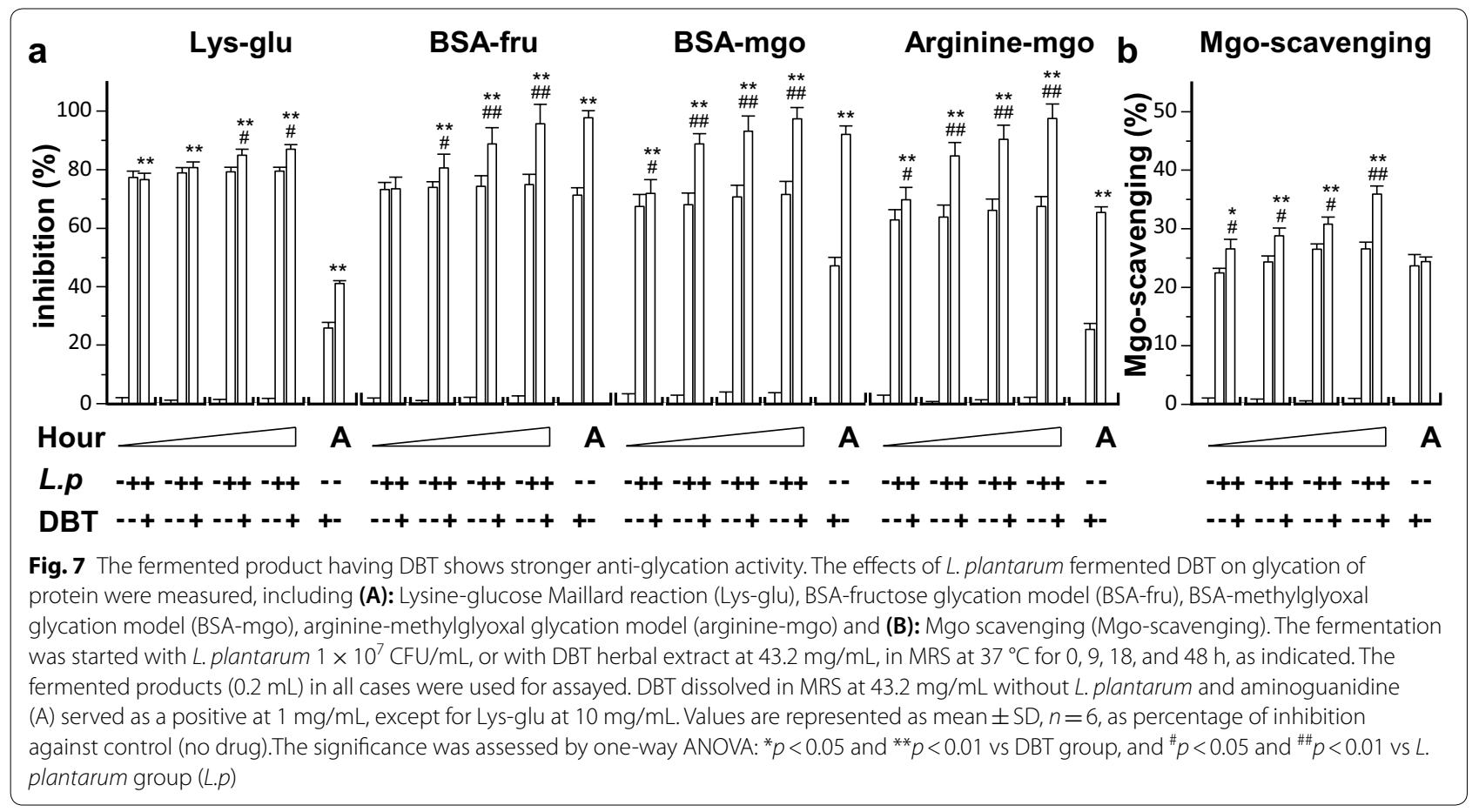

From reading of fluorescent AGE, the fermentation of DBT displayed higher anti-glycation activity in a timedependent manner (Fig. 7). In arginine-methylglyoxal model, the formation of AGE was suppressed by DBT, and which was markedly enhanced by fermentation: the maximal inhibition was close to a completion (Fig. 7). Similar to the aforementioned anti-glycation activities, DBT was able to inhibit the scavenging activity, and the activity was markedly enhanced after fermentation with L. plantarum (Fig. 7). Aminoguanidine served as a positive control here showing inhibition in all cases.

\section{Discussion}

Fermentation of L. plantarum together with a Chinese herbal mixture DBT could enhance the bacterial growth, as well as the chemical transformation of herbal extract. In chemical transformation, the major flavonoid glucosides of DBT were hydrolyzed into their corresponding aglycones: this conversion was mediated by $\beta$-glucosidase deriving from fermented bacteria. For the first time, we have utilized $L$. plantarum bacteria in strengthen the pharmacological efficacy of DBT. The fermented DBT showed better effects in anti-diabetic functions, which included: (i) inhibitory properties on $\alpha$-glucosidase; (ii) antioxidant properties on DPPH scavenging and T-AOC; and (iii) anti-glycation capacity on various models. This fermentation approach, nevertheless, could be considered as a mean to enhance the pharmacological efficacy of TCM in general. The safety should not be a concern: because $L$. plantarum is a common Lactobacillus found in many fermented food products, as well as in human saliva, which has been known to show no harm to our body. Having this new direction of fermentation of Chinese herbal extract therefore can pave another method to enhance the product efficacy, in particular Lactobacillus and herbal product are commonly used as health food products on the market.

The UPLC-MS/MS analysis is a common method for simultaneous quantitation of flavonoid compounds. However, most of the developed methods are focusing on herbal or plasma samples. No reports have investigated the simultaneously quantitative analysis of the flavonoids in the fermented broth of $L$. plantarum. The method development of MS parameters, as well as method validation comprising parameters, e.g. specificity, linearity, sensitivity, precision and accuracy, extract efficiency, matrix effects and stability, is being described in detail at the present study. Thus, a sensitive and reliable quality control method using MRM in negative ion mode for simultaneous determination of four flavonoids in fermented DBT, i.e. calycosin-7-O- $\beta$-D-glucoside, ononin, calycosin and formononetin, has been developed.

The chemical transformation, i.e. cleavage of the sugar moieties, was observed in here. The enzyme $\beta$-D-glucosidase is responsible for the cleavage of $\beta$-Dglycosidic linkages, releasing glucose moieties from flavonoid glycosides [39]. This enzyme should derive from the cultured medium of $L$. plantarum, not from the 
herbal extract. The expression of $\beta$-D-glucosidase in the fermented product, as revealed by release of p-nitrophenol from $p$-nitropheny- $\beta$ - $D$-glucopyranoside, could be markedly enhanced in DBT extract. A synergy during the fermentation of DBT with L. plantarum is being proposed here. First, DBT promoted the expression of $\beta$-D-glucosidase in fermenting L. plantarum. Second, the produced $\beta$-D-glucosidase hydrolyzed the flavonoid glycosides of DBT to aglycons. These findings suggested that an improvement in hydrolysis rate of glycoside enzymes perhaps may be ascribed to DBT inducement. In TCM preparation, the phytochemicals exhibit low oral bioavailability, in particular glycosides are possessing poor membrane permeability [40]. Moreover, these glycosides are inevitable to be transformed by microbial hydrolysis in intestinal before their absorption to the gut [41]. Herein, the role of $\beta$-D-glucosidase in food and/or pharmaceutical bioprocessing could promote aglycone entering blood circulation [42].

The anti-diabetic functions of fermented products should be derived from DBT. The chemical changes within DBT after fermentation could account for increased pharmacological efficacy. However, the identity of active chemicals of DBT in triggering these activities are not resolved. The increased antioxidant property could be accounted for the hydrolyzed flavonoid glycosides. Indeed, aglycons in the herbal extract were shown to have stronger antioxidative activity [43]. Although we have shown the increased calycosin and formononetin being generated from calycosin-7-O- $\beta$-D-glucoside and ononin, respectively, in the fermented DBT, the amounts of total aglycons should be more than that, i.e. other flavonoid glycosides in DBT should be undergone the transformation. In our preliminary results of the four AR flavonoids, the increased activities however could not be fully accounted by completed hydrolyzed of calycosin-7$\mathrm{O}-\beta$-D-glucoside and ononin. The inhibitory properties of $\alpha$-glucosidase and glycation increased in the fermented DBT. The $\alpha$-glucosidase inhibitory activity from natural products has been proposed to be accounted by flavone, in particular isoflavone [44]. In line to our current result of chemical conversion, flavonoid glucosides possessed a relatively poor inhibitory action on $\alpha$-glucosidase, as compared with their corresponding aglycones [40].

The non-enzymatic glycation, a spontaneous reaction between sugar and protein, is considered as a source of oxidative stress, as well as the primary route in forming AGEs. Increased AGE has been implicated in the pathogenesis of diabetic complication. The increased anti-glycation activity in fermented DBT could be accounted by the conversion of flavonoid glucosides to aglycons. Various phenolic compounds, inhibiting $\alpha$-glucosidase, have been reported as inhibitors of glycoside hydrolase due to their binding with proteins, as such to erode the glycation reaction [38]. The hydrolysis of polysaccharides within DBT during fermentation could be another cause of the increased anti-glycation activity; however, this notion has to be further illustrated.

\section{Conclusions}

To the best of our knowledge, we have reported for the first time, the conversion of calycosin-7-O- $\beta$-D-glucoside and ononin to their aglycons in DBT through a fermentation process using $L$. plantarum. In considering the traditionally oral intake of herbal medicine, the conversion of flavonoid glycosides in fermented DBT not only improves the absorptivity of flavonoids to gut, but which possess prominent activities against $\alpha$-glucosidase, antioxidant and anti-glycation. These anti-diabetic activities could be accounted, at least partially, by the increased flavonoid aglycons in the fermented products. The result paves direction for fermentation of herbal extract, as to strengthen its pharmacological properties.

\section{Supplementary information}

Supplementary information accompanies this paper at https://doi. org/10.1186/s13020-020-00379-x.

Additional file 1: Figure S1. Typical-HPLC fingerprints of DBT before and after fermentation. Table S1. Analytic parameters of 4 standards by UPLCMS/MS in fermented DBT.

\section{Abbreviations}

AGE: The fluorescent advanced glycation end-product; ASR: Angelicae Sinensis Radix; AR: Astragali Radix; BSA: Bovine serum albumin; CCL: Collision cell lens; CE: Collision energy; Ctrl.: Control; DBT: Danggui Buxue Tang; EV: Entrance voltage; HQC: High quality control; IS: Internal standard; LLOQ: Lower limit of quantification; L. plantarum: Lactobacillus plantarum; LOD: Limit of detection; LQC: Low quality control; 2-MQ: 2-Methylquinoxaline; MQC: Middle quality control; MRM: Multiple reactions monitoring; MRS: De Man, Rogosa, Sharpe; OD: Optical density; O-PD: O-phenylenediamine; PNP: P-nitrophenol; PNP-D-Glu: P-nitropheny- $\beta$-D-glucopyranoside; PNPP: P-nitrophenylpalmitate; QC: Quality control; RE: Relative error; RSD: Relative standard deviation; T-AOC: Total antioxidant capacity; TCM: Traditional Chinese medicine; T2DM: Type 2 diabetes mellitus.

\section{Acknowledgements}

Not applicable.

\section{Authors' contributions}

KT and RG conceived and designed the experiments. RG performed the experiments, analyzed the results, and made figures and tables. SG, XG, HW and $\mathrm{WH}$ performed the experiments. RD and TD contributed to designing the experiments. KT and RG wrote the paper. All authors read and approved the final manuscript.

\section{Funding}

This work is supported by Shenzhen Science and Technology Innovation Committee (ZDSYS201707281432317; JCYJ20170413173747440; JCYJ20180306174903174), China Post-doctoral Science Foundation (2019M653087), Zhongshan Municipal Bureau of Science and Technology (ZSST20SC03); Foshan-HKUST Project Funding (FSUST19-SRI10); Guangzhou Science and Technology Committee Research Grant (GZSTI16SC02; GZSTI17SC02; GICI20SC01); Hong Kong RGC Theme-based Research Scheme 
(T13-605/18-W); Hong Kong Innovation Technology Fund (UIM/340, UIM/385, ITS/500/18FP; TCPD/17-9); TUYF19SC02, PD18SC01 and HMRF18SC06.

\section{Availability of data and materials}

The datasets used and/or analyzed during the current study are available from the corresponding author on reasonable request.

\section{Ethics approval and consent to participate}

Not applicable.

\section{Consent for publication}

All authors consent to publication of this study in the journal Chinese Medicine.

\section{Competing interests}

The authors declare that they have no competing interests.

\section{Author details}

${ }^{1}$ Shenzhen Key Laboratory of Edible and Medicinal Bioresources, HKUST Shenzhen Research Institute, Shenzhen 518057, China. ${ }^{2}$ Key Laboratory of Innovative Drug for the Treatment of Serious Diseases Basing on the Chronic Inflammation, Shanxi University of Chinese Medicine, 121 Daxue Road, Yuci District, Jinzhong 030619, China. ${ }^{3}$ Division of Life Science and Center for Chinese Medicine, The Hong Kong University of Science and Technology, Hong Kong, China.

Received: 28 May 2020 Accepted: 5 September 2020

Published online: 11 September 2020

\section{References}

1. Al-Habori M, Al-Mamari M, Al-Meeri A. Type II Diabetes Mellitus and impaired glucose tolerance in Yemen: prevalence, associated metabolic changes and risk factors. Diabetes Res Clin Pract. 2004;65:275-81.

2. IDF DIABETES ATLAS 9th edition. 2020. www.diabetesatlas.org/en/secti ons/worldwide-toll-of-diabetes.html. Accessed 28 May 2020.

3. Nathan DM. Diabetes: advances in diagnosis and treatment. JAMA. 2015;314(10):1052-62

4. Meneilly GS, Tessier DM. Diabetes, dementia and hypoglycemia. Can J Diabetes. 2016;40(1):73-6.

5. Bonnet F, Scheen A. Understanding and overcoming metformin gastrointestinal intolerance. Diabetes Obes Metab. 2017;19(4):473-81.

6. Ning G, Hong J, Bi YF, Gu WQ, Zhang YF, Zhang ZG, Huang Y, Wang WQ, Li $X Y$. Progress in diabetes research in China. J Diabetes. 2009;1(3):163-72.

7. Gao QT, Choi RCY, Cheung AWH, Zhu JTT, Li J, Chu GKY, Duan R, Cheung JKH, Jiang ZY, Dong XB, Zhao KJ, Dong TTX, Tsim KWK. Danggui Buxue Tang - a Chinese herbal decoction activates the phosphorylations of extracellular signal-regulated kinase and estrogen receptor a in cultured MCF-7 cells. FEBS Lett. 2007;581(2):233-40.

8. Zhang WL, Choi CY, Zhan YX, Chen JP, Luk KW, Yao P, Dong TX, Tsim KW. Can Hedysari Radix replace Astragali Radix in Danggui Buxue Tang, a Chinese herbal decoction for woman aliment? Phytomedicine. 2013;20(12):1076-81.

9. Zierau O, Zheng KYZ, Papke A, Dong TTX, Tsim KWK, Vollmer G. Functions of Danggui Buxue Tang, a Chinese herbal decoction containing Astragali Radix and Angelicae Sinensis Radix, in uterus and liver are both estrogen receptor-dependent and -independent. Evid Based Complement Alternat Med. 2014;2014:1-11.

10. Wang X, Bei H, Du R, Chen Q, Wu F, Chen J, Bo H. Metabolomic analysis of serum reveals the potential effective ingredients and pathways of Danggui Buxue Tang in promoting erythropoiesis. Complement Ther Med. 2020;48:102247.

11. Gao QT, Cheung JK, Li J, Chu GK, Duan R, Cheung AW, Zhao KJ, Dong TT, Tsim KW. A Chinese herbal decoction, Danggui Buxue Tang, prepared from Radix Astragali and Radix Angelicae Sinensis stimulates the immune responses. Planta Med. 2006;72(13):1227-311.

12. Song ZH, Ji ZN, Lo CK, Dong TT, Zhao KJ, Li OT, Haines CJ, Kung SD, Tsim KW. Chemical and biological assessment of a traditional Chinese herbal decoction prepared from Radix Astragali and Radix Angelicae Sinensis:
Orthogonal array design to optimize the extraction of chemical constituents. Planta Med. 2004;70(12):1222-7.

13. Choi RC, Gao QT, Cheung AW, Zhu JT, Lau FT, Li J, Li WZ, Chu GK, Duan R, Cheung JK, Ding AW, Zhao KJ, Dong TT, Tsim KW. A Chinese herbal decoction, Danggui Buxue Tang, stimulates proliferation, differentiation and gene expression of cultured osteosarcoma cells: Genomic approach to reveal specific gene activation. Evid Based Complement Alternat Med. 2011;2011:1-13.

14. Zhang Y, Xie D, Xia B, Zhen R, Liu IM, Cheng JT. Suppression of transforming growth factor- $\beta 1$ gene expression by Danggui Buxue Tang, a traditional Chinese herbal preparation, in retarding the progress of renal damage in streptozotocin-induced diabetic rats. Horm Metab Res. 2006;38(2):82-8.

15. Liu IM, Tzeng TF, Liou SS. A Chinese herbal decoction, Dang Gui Bu Xue Tang, prepared from Radix Astragali and Radix Angelicae sinensis, ameliorates insulin resistance induced by a high-fructose diet in rats. Evid Based Complement Alternat Med. 2011;2011:1-11.

16. Zhang R, Han X, Huang T, Wang X. Danggui Buxue Tang inhibited mesangial cell proliferation and extracellular matrix accumulation through GAS5/NF-kB pathway. Biosci Rep. 2019. https://doi.org/10.1042/BSR20 181740.

17. Qi WL, Cao J, Li P, Wang YX. Rapid and sensitive quantitation of major constituents in Danggui Buxue Tang by ultra-fast HPLC-TOF/MS. J Pharm Biomed Anal. 2009;49(2):502-7.

18. Shen P, Liu MH, Ng TY, Chan YH, Yong EL. Differential effects of isoflavones, from Astragalus Membranaceus and Pueraria Thomsonii, on the activation of ppara, ppary, and adipocyte differentiation in vitro. J Nutr. 2006;136(4):899-905

19. Barnes S, Prasain J, D'Alessandro T, Arabshahi A, Botting N, Lila MA, Jackson G, Janle EM, Weaver CM. The metabolism and analysis of isoflavones and other dietary polyphenols in foods and biological systems. Food Funct. 2011;2(5):235-44

20. Zhao H, Zhang Y, Guo Y, Shi S. Identification of major a-glucosidase inhibitors in Radix Astragali and its human microsomal metabolites using ultrafiltration HPLC-DAD-MSn . J Pharm Biomed Anal. 2015;104:31-7.

21. Dueñas M, Surco-Laos F, González-Manzano S, González-Paramás AM, Gómez-Orte E, Cabello J, Santos-Buelga C. Deglycosylation is a key step in biotransformation and lifespan effects of quercetin-3-O-glucoside in Caenorhabditis elegans. Pharmacol Res. 2013;76:41-8.

22. Shi J, Zheng H, Yu J, Zhu L, Yan T, Wu P, Lu L, Wang Y, Hu M, Liu Z. Sglt-1 transport and deglycosylation inside intestinal cells are key steps in the absorption and disposition of calycosin-7-O-D-glucoside in rats. Drug Metab Dispos. 2015;44:283-96.

23. Choi CW, Choi YH, Cha MR, Yoo DS, Kim YS, Yon GH, Hong KS, Kim YH, Ryu SY. Yeast a-glucosidase inhibition by isoflavones from plants of Leguminosae as an in vitro alternative to acarbose. J Agric Food Chem. 2010;58(18):9988-93.

24. Xu C, Ji GE. Bioconversion of flavones during fermentation in milk containing Scutellaria baicalensis extract by Lactobacillus brevis. J Microbiol Biotechnol. 2013;23(10):1422-7.

25. Wang J, Bose S, Kim H, Han K, Kim H. Fermented Rhizoma Atractylodis Macrocephalae alleviates high fat diet-induced obesity in association with regulation of intestinal permeability and microbiota in rats. Sci Rep. 2015;5:8391.

26. Oh J, Jeon SB, Lee Y, Lee H, Kim J, Kwon BR, Yu KY, Cha JD, Hwang SM, Choi KM, Jeong YS. Fermented red ginseng extract inhibits cancer cell proliferation and viability. J Med Food. 2015;18(4):421-8.

27. Hur SJ, Lee SY, Kim YC, Choi I, Kim GB. Effect of fermentation on the antioxidant activity in plant-based foods. Food Chem. 2014;160:346-56.

28. Ma XQ, Duan JA, Zhu DY, Dong T, Tsim KWK. Chemical comparison of Astragali Radix (Huangqi) from different regions of China. Nat Med. 2000:54(5):213-8

29. Zhao K, Dong T, Tu P, Song Z, Lo C. Molecular genetic and chemical assessment of Radix Angelica (Danggui) in China. J Agric Food Chem. 2003;51:2576-83.

30. Yılmaz T, Simşek ÖJM. Potential health benefits of ropy exopolysaccharides produced by Lactobacillus plantarum. Molecules. 2020;25(14):3293.

31. Wang HY, Guo SC, Peng ZT, Wang C, Duan R, Dong TTX, Tsim KWK. Ophiopogon polysaccharide promotes the in vitro metabolism of ophiopogonins by human gut microbiota. Molecules. 2019;24(16):2886. 
32. Zhang Y, Yang Z, Liu G, Wu Y, Ouyang J. Inhibitory effect of chestnut (Castanea mollissima Blume) inner skin extract on the activity of a-amylase, a-glucosidase, dipeptidyl peptidase IV and in vitro digestibility of starches. Food Chem. 2020;324:126847.

33. Justino AB, Miranda NC, Franco RR, Martins MM, Silva NMD, Espindola FS. Annona muricata Linn. Leaf as a source of antioxidant compounds with in vitro antidiabetic and inhibitory potential against a-amylase, a-glucosidase, lipase, non-enzymatic glycation and lipid peroxidation. Biomed Pharmacother. 2018;100:83-92.

34. Franco RR, Mota Alves VH, Ribeiro Zabisky LF, Justino AB, Martins MM, Saraiva AL, Goulart LR, Espindola FS. Antidiabetic potential of Bauhinia forficata Link leaves: A non-cytotoxic source of lipase and glycoside hydrolases inhibitors and molecules with antioxidant and antiglycation properties. Biomed Pharmacother. 2020;123:109798.

35. Zuo AR, Dong HH, Yu YY, Shu QL, Zheng LX, Yu XY, Cao SW. The antityrosinase and antioxidant activities of flavonoids dominated by the number and location of phenolic hydroxyl groups. Chin Med. 2018;151:42-8

36. Liu F, Qu YK, Geng C, Wang AM, Zhang JH, Chen KJ, Liu B, Tian HY, Yang WP, Yu YB. Effects of hesperidin on the growth performance, antioxidant capacity, immune responses and disease resistance of red swamp crayfish (Procambarus clarkii). Fish Shellfish Immunol. 2020;99:154-66.

37. Kuda T, Eda M, Kataoka M, Nemoto M, Kawahara M, Oshio S, Takahashi H, Kimura B. Anti-glycation properties of the aqueous extract solutions of dried algae products and effect of lactic acid fermentation on the properties. Food Chem. 2016;192:1109-15.

38. Abbasi S, Gharaghani S, Benvidi A, Rezaeinasab M. New insights into the efficiency of thymol synergistic effect with p-cymene in inhibiting advanced glycation end products: a multi-way analysis based on spectroscopic and electrochemical methods in combination with molecular docking study. J Pharm Biomed Anal. 2018;150:436-51.

39. Guadamuro L, Flórez AB, Alegría Á, Vázquez L, Mayo B. Characterization of four $\beta$-glucosidases acting on isoflavone-glycosides from Bifidobacterium pseudocatenulatum IPLA 36007. Food Res Int. 2017;100:522-8.

40. Ruan JQ, Li S, Li YP, Wu WJ, Lee SM, Yan R. The presystemic interplay between gut microbiota and orally administered calycosin-7-O-D-glucoside. Drug Metab Dispos. 2015;43:1601-11.

41. Gao MX, Tang XY, Zhang FX, Yao ZH, Yao XS, Dai Y. Biotransformation and metabolic profile of Xian-Ling-Gu-Bao capsule, a traditional Chinese medicine prescription, with rat intestinal microflora by ultra-performance liquid chromatography coupled with quadrupole time-of-flight tandem mass spectrometry analysis. Biomed Chromatogr. 2018;32(4):e4160. https $\cdot / /$ doi.org/10.1002/bmc.4160.

42. Liu QX, Hui-Liang LI, Liu RH. Application of microbial transformation in natural products research. J Pham Pract. 2012;5:321-5 (in Chinese).

43. Yu DH, Bao YM, Wei CL, An LJ. Studies of chemical constituents and their antioxidant activities from Astragalus Mongholicus bunge. Biomed Environ Sci. 2005;18:297-301.

44. Liu Y, Nyberg NT, Jäger AK, Staerk D. Facilitated visual interpretation of scores in principal component analysis by bioactivity-labeling of ${ }^{1} \mathrm{H}$ NMR spectra-metabolomics investigation and identification of a new a-glucosidase inhibitor in Radix Astragali. Molecules. 2017;22:411.

\section{Publisher's Note}

Springer Nature remains neutral with regard to jurisdictional claims in published maps and institutional affiliations.
Ready to submit your research? Choose BMC and benefit from:

- fast, convenient online submission

- thorough peer review by experienced researchers in your field

- rapid publication on acceptance

- support for research data, including large and complex data types

- gold Open Access which fosters wider collaboration and increased citations

- maximum visibility for your research: over $100 \mathrm{M}$ website views per year

At BMC, research is always in progress.

Learn more biomedcentral.com/submissions 